\title{
Videocolaboração no Hospital Militar de Área de São Paulo - Exército Brasileiro
}

\author{
Mauricio M. M. Segobia \\ Hospital Militar de Área de São Paulo \\ R. Ouvidor Portugal, 230, São Paulo, SP \\ segobia01@gmail.com \\ Paulo M. Porto de Melo \\ Clínica de Neurocirurgia-Hospital \\ Militar de Área de São Paulo \\ R. Ouvidor Portugal, 230, \\ São Paulo, SP \\ drpauloportodemelo@gmail.com
}

\author{
Claudia Galindo Novoa \\ Telessaúde São Paulo/ \\ Universidade Federal de São Paulo \\ Rua Pedro de Toledo, 715.SãoPaulo \\ claudia.novoa@unifesp.br \\ Jane de Almeida \\ PPGEAHC/LIC-Unicamp/Universidade \\ Mackenzie \\ Rua Consolação,930.SãoPaulo-SP \\ janedealmeida@post.harvard.edu
}

\author{
Cicero I. da Silva \\ Telessaúde São Paulo/ \\ Universidade Federal de São Paulo \\ (UNIFESP) \\ Rua Pedro de Toledo, 715 \\ São Paulo, SP \\ cicero.silva@unifesp.br
}

\begin{abstract}
This article analyzes the experience of the São Paulo Military Hospital (HMASP) in the area of digital health, telemedicine and telehealth. The goal is to present the state of the art of digital health at the HMASP, a history of its recent implementation and the challenges regarding the technological conditions existing in the field of videocolaboration for surgery and teleassistance. The article also analyzes some experiences in the area of telemedicine used at the HMASP by the Brazilian Army and also lists future challenges regarding the intensive use of videocolaborative processes in digital health.
\end{abstract}

\section{KEYWORDS}

e-health, telemedicine,video conferece,military, brazilianarmy

\section{Saúde Digital, Telemedicina e o Exército Brasileiro}

A sociedade da informação em que vivemos caracteriza-se por ser uma comunidade cujo funcionamento recorre de forma crescente às redes digitais de informação. Os setores potencialmente mais influenciados serão aqueles que lidam com maiores volumes de informação, como é o caso da saúde. A telemedicina trata do uso das modernas tecnologias da informação e telecomunicações para o fornecimento de informação e atenção médica a pacientes e outros profissionais de saúde situados em locais distantes. Como uma das ferramentas de apoio à Telemedicina existe a videocolaboração, que traz diversas vantagens tanto para área técnica/cirúrgica, como para a área de educação em saúde e, consequentemente, ao ensino por meio do uso de recursos de

In: VI Workshop “O Futuro da Videocolaboração" (WCT-Video 2019), Rio de Janeiro, Brasil. Anais Estendidos do Simpósio Brasileiro de SistemasMultimídia e Web (WebMedia). Porto Alegre: Sociedade Brasileira de Computação, 2019.

(C) 2019 SBC - Sociedade Brasileira de Computação.

ISSN: 2596-1683 saúde digital. Dentre essas vantagens, pode se destacar a possibilidade de transmissão de cirurgias em tempo real via streaming, alcançando um enorme número de participantes visando a colaboração médica em situações de ensino e pesquisa. Com uma boa infraestrutura de TI visando qualidade de imagem e som, praticamente pode-se "colocar" a equipe de profissionais de saúde dentro do centro cirúrgico [1]. Equipe esta que pode, muitas vezes, interagir ao vivo com a equipe médica. $\mathrm{O}$ interesse do Exército Brasileiro pela telemedicina ocorreu em 2004, a convite do Professor Doutor Gyorgy Miklos Bohm, então Presidente do Conselho Brasileiro de Telemedicina e Telessaúde. Assim, por intermédio da Portaria $\mathrm{n}^{\circ} 190$ de 20 de abril, do Comandante do Exército, expediu-se a diretriz para participação no referido conselho e, dentre os objetivos estabelecidos pela Portaria, caberia ao Departamento-Geral do Pessoal (DGP) do Exército definir a prioridade de emprego da telemedicina para o apoio às regiões mais carentes do campo de saúde do Exército Brasileiro.

\section{Videocolaboração para Gestão Médica e segunda opinião formativa}

Em 2014, por meio do DGP, deu-se início a um programa piloto para apoio em Neurocirurgia às Organizações de Saúde Militares que não possuem neurocirurgiões militares. Este programa acontece por meio de videoconferências quinzenais. Desde então, para as videoconferências, as Organizações Militares de Saúde (OMS) recebem um link (IP, Sala Virtual e Gatekeeper), por meio de uma Multi Point Control Unit (MCU), do Comando de Operações Terrestres (COTER). Assim, coordena-se a interligação das diferentes organizações, que passam a integrar um mesmo ambiente virtual, conectados na intranet do Exército Brasileiro (EBNet), provida pela Rede Operacional de Defesa (ROD), atendendo o princípio da segurança de rede corporativa e privacidade dos dados. Neste ambiente, cada Organização de 
Saúde pode conectar-se às salas por meio de um aparelho de videoconferência ou via Web.

Esta MCU permite a conexão simultânea de até 32 participantes, com transmissão de vídeo e voz, síncrona. As sessões de videoconferência destinam-se à discussão de casos clínicos na especialidade de Neurocirurgia, definição de condutas e coordenação de transferências dos casos que tiverem indicação (Figura 1). As doze Regiões Militares do Exército Brasileiro têm participado, representadas pelo Chefe da Seção de Saúde Regional e por algum médico do Hospital mais próximo. No HMASP, estas videoconferências são realizadas através de 2 canais de vídeo 1080p/60fps simultâneos para vídeo e conteúdo ao vivo, zoom óptico da câmera 10x, zoom digital 4x, 40x total, utilizando-se do aparelho Scopia XT1500.

A sistematização da discussão de casos na área de neurocirurgia entre as OMS tem promovido uma maior seletividade na indicação de cirurgias, evitando a realização de procedimentos não amparados em protocolos científicos nas regiões de origem e evitado transferências desnecessárias de pacientes [2]. Um dos adventos da adoção de videocolaboração foi a redução significativa de custos com cirurgias que haviam sido indicadas por médicos civis e que, após avaliação dos neurocirurgiões militares, foram contraindicadas, tendo como resultado uma economia de alto valor orçamentário, sem prejuízo algum para os pacientes [3].

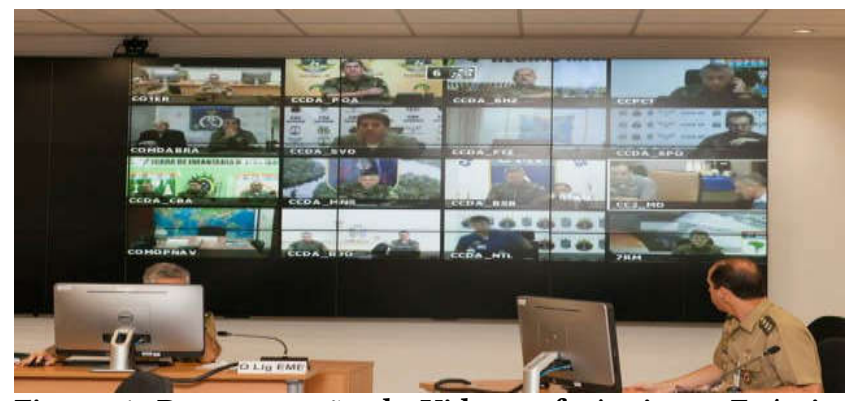

Figura 1: Demonstração de Videoconferência no Exército Brasileiro

Sem contar com os custos que adviriam do afastamento dos militares do trabalho, com os deslocamentos, hospedagem, diárias, entre outras necessidades.

$\mathrm{Na}$ área de pesquisa e desenvolvimento, existe a previsão para que o Hospital Militar de Área de São Paulo (HMASP) passe a integrar a Rede Universitária de Telemedicina (RUTE) da Rede Nacional de Ensino e Pesquisa (RNP), bem como participar das reuniões clínicas de neurocirurgia da Universidade de Saint Louis e da Universidade Federal de São Paulo (Unifesp) - entidades civis parceiras na execução do programa de residência médica em neurocirurgia naquela OMS.

O uso dos protocolos de videocolaboração operam em três vertentes no campo da saúde digital/telemedicina/telessaúde: multiplicação do conhecimento, coordenação e controle dos pacientes e educação a distância (educação permanente em saúde), trazendo benefícios assistenciais, gerenciais (financeiros e de consciência situacional) e acadêmicos, como podemos observar na seção 3.

\section{Transmissão ao vivo de Cirurgia para implante de Cage Tlif Expansível para Coluna Lombar}

Em março de 2019 o Hospital Militar de Área de São Paulo (HMASP) recebeu a visita dos médicos Profs. Drs. Oscar Alves, Neurocirurgião e de Massimo Balsano, Ortopedista. Ambos, juntamente com a equipe de Neurocirurgia do HMASP, chefiada pelo Cap. Med. P. Porto, participaram de duas cirurgias, sendo uma delas a primeira, no Brasil, a utilizar um cage expansível para coluna lombar, também denominado deCage Tlif Expansível, um implante conhecido também como espaçador vertebral.

Nesta cirurgia, coordenada pelo Prof. Massimo, com a participação do Cap.Med. P. Porto, o paciente apresentava hérnia de disco e foi o primeiro no Brasil a receber esse implante. Comparado aos outros cages que possuem maior espessura, o cage expansível é introduzido com $6 \mathrm{~mm}$ de espessura e no local a ser implantado ele se expande em até $10 \mathrm{~mm}$, causando menos danos ao paciente. Com um tamanho de corte menor, há menor dano ao tecido,músculo e ligamentos; além disso, há menos sangramento, menor risco de infecção. Desta forma, a cicatrização é mais rápida. A cirurgia foi filmada diretamente do foco cirúrgico com microscópio Leica ${ }^{\circledR}$ M530 OH6, mostrando com mínimos detalhes todo os procedimentos realizados. A cirurgia foi transmitida em tempo real via streaming para mais de 20 participantes (residentes e convidados), localizados no auditório do HMASP e para mais de 90 telespectadores através do link disponibilizado na internet para usuários autenticados [4].A distância entre o centro cirúrgico e o auditório que receberia a transmissão era de 400 metros e nãohaviano caminho shafts para lançamento de fios e, mesmo que existissem, seria uma distância fora dos padrões para ligações por fios.Esta conexão somente se fez possível através da utilização de um par de conversores HDMI/RJ45, conforme diagrama:

Figura 2: Diagrama ligação microscópio (Centro Cirúrgico) e Auditório HMASP.

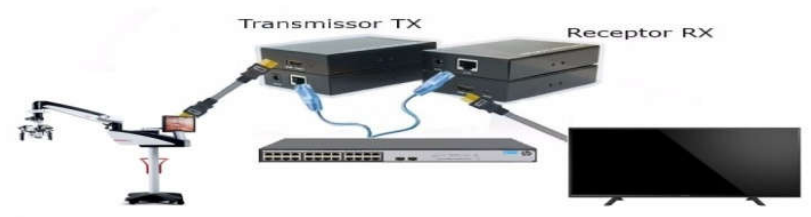

Nesta estrututura, pluga-se um cabo HDMI na saída de video do microscópio e na entrada do conversor (transmissor RX), que por sua vez converte o sinal recebido para a saída RJ45. Desta forma a distância não é mais um fator limitante, pois pode propagar o sinal convertido através de switches (camada 3) até o destino final 
Saúde Digital e Videocolaboração no Hospital Militar de Área de São Paulo (HMASP) do Exército Brasileiro

(receptor RX), ondeeste reconverte o sinal através da saída HMDI e pluga-se na TV do auditório através de cabo.

Ainda foi disponibilizado um canal de voz, (utilizando-se as principais funções do software OBS Studio), entre a equipe médica e os residentes presentes no auditório, permitindo interação e retirada de dúvidas em tempo real durante a cirurgia. Este canal foi compartilhado também para os participantes conectados via Web, como ouvintes.

Figura 2: Cap. P. Porto apresenta os detalhes da primeira cirurgia para os internautas conectados através do link de streaming.
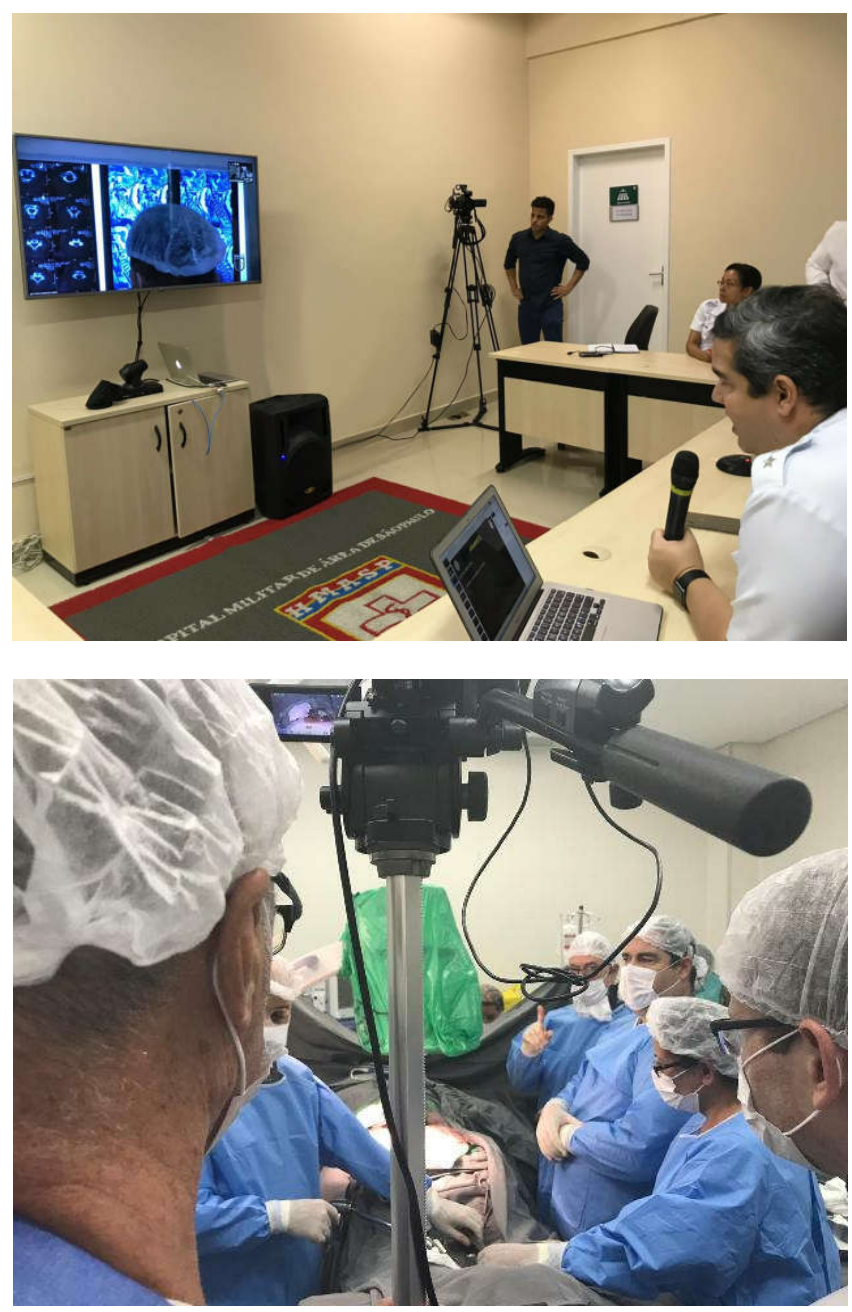

Figura 3:Equipe Médica utilizando a estrutura de áudio e vídeo instalada no Centro Cirúrgico.
Anais Estendidos do WebMedia'2019, Rio de Janeiro, Brasil

A Saúde Digital, os protocolos de telemedicina e telessaúde, a educação permanente por meio do uso de Tecnologias da Informação e da Comunicação (TICs), além da teleassistência em saúde têm sido os principais motivadores da redução de deslocamentos, diminuição nos encaminhamentos de pacientes e, por conseqüência, promovido uma economia de recursos com manutenção da qualidade do atendimento dos pacientes no Exército Brasileiro. Neste sentido, para que a Saúde Digital continue se aperfeiçoando no Exército Brasileiro, principalmente no Hospital Militar de Área de São Paulo (HMASP), as equipes responsáveis traçaram como metas:

1. A conexão do HMASP à Rede Universitária de Telemedicina (RUTE) da Rede Nacional de Ensino e Pesquisa (RNP): o HMASP tem a intenção de iniciar sua participação em alguns SIGs (Special Interest Groups) hoje disponibilizados pela RUTE. Os SIGs podem servir de oportunidade para a troca de valiosas informações entre os grupos de pesquisa do Brasil na área de telemedicina e telessaúde[5];

2. O desenvolvimento de estudos de viabilidade da participação do HMASP junto ao Programa de Saúde Digital (Telessaúde São Paulo) da Universidade Federal de São Paulo (Unifesp): existe a possibilidade de o Programa Telessaúde Unifesp participar de algumas ações de telessaúde junto ao HMASP, tais como ações de teleducação em saúde, com a oferta de cursos, seminários, formações avançadas, web e videoconferências, entre outras, que atuem no campo da Educação Permanente em saúde no HMASP;

3. A disponibilidade de redes avançadas para provimento de banda dedicada com conexão a partir de $10 \mathrm{Gbps}$, a princípio com estudos de instalação sendo executados pela rede ANSP (an Academic Network at São Paulo): está em estudo a implantação de uma rede Gigabit dedicada, a ser disponibilizada pela Rede ANSP no HMASP. Esta rede será prioritariamente utilizada pelas pesquisas na área de videocolaboração, pois os experimentos serão realizados em ultra-alta definição e serão necessários vários sistemas de transmissão (streaming) robustos para dar suporte a quantidade de dados a ser transportada;

4. A disponibilidade de sistemas de transmissão cirúrgica em ultra-alta definição (4K ou acima) para os centros cirúrgicos dos Hospitais de Área do Exército Brasileiro: os estudos indicam a necessidade de se ampliar o espectro de ações em ultra-alta definição, principalmente nos aspectos tecnológicos para explorar as capacidades de videocolaboração em UHD (ultra high definition) em saúde [6].

\section{Próximos passos}




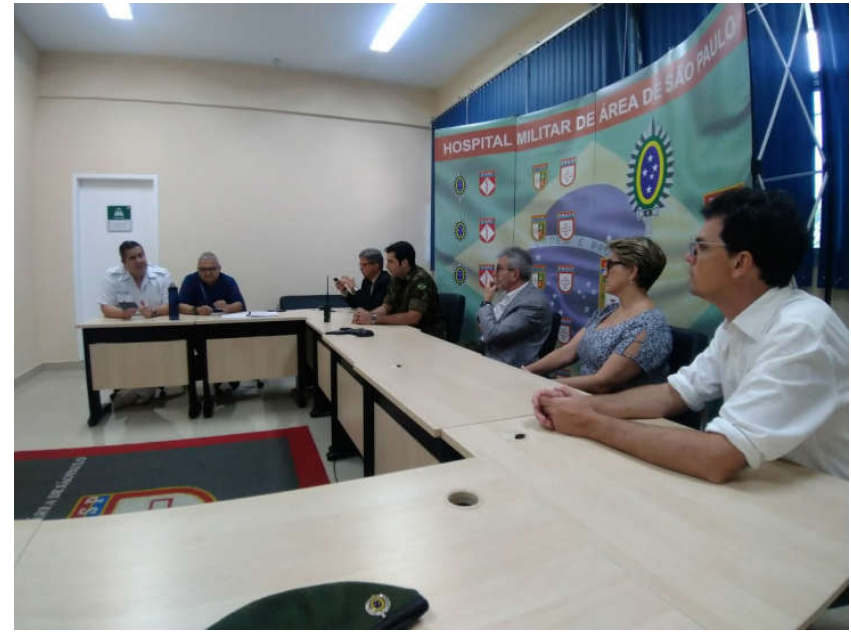

Figura 4:Reunião da Coordenação da Rede ANSP e do Telessaúde São Paulo Unifesp com a equipe de Saúde Digital do HMASP.

\section{Conclusão}

O uso dos recursos disponibilizados pelas redes avançadas e pelas tecnologias de transmissão de imagem em ultra-alta definição têm cada vez mais possibilitado inúmeras pesquisas e ações práticas no campo da telemedicina, telessaúde e educação permanente em saúde, como observamos nos exemplos acima. $\mathrm{O}$ uso dos recursos tecnológicos de videocolaboração nas ações de saúde digital podem abrir cada vez mais novos campos de investigação, não sendo mais só utilizados como recursos de teleconferência para reuniões, mas em situações de procedimentos reais com pacientes, salvando vidas e melhorando a qualidade do atendimento, além da resolutividade em casos complexos. Neste sentido, é importante salientar que este trabalho, dados os recentes desenvolvimentos tecnológicos em transmissão e recepção de vídeos, têm sido realizado com bastante sucesso e depende de profissionais capacitados que possam, diariamente, atualizar o parque tecnológico na área de videocolaboração, para que a saúde digital continue sua evolução tecnológica sem esquecer do seu principal objetivo, a melhora das condições humanas de saúde do efetivo Militar do Exército Brasileiro, de seus familiares e de seus colaboradores civis e militares.

\section{AGRADECIMENTOS}

Agradecemos à Direção, equipes de saúde digital e Clínica de Neurocirurgia do HMASP, do Telessaúde São Paulo Unifesp, à Rede ANSP e ao Grupo de Pesquisa em Saúde Digital: Telessaúde e Tecnologias da Informação da Unifesp (http://dgp.cnpq.br/dgp/espelhogrupo/1179489123867343).

\section{REFERÊNCIAS}

[1] KHOURI, S. Telessaúde: análise da sua evolução no Brasil. 2003. Dissertação (Mestrado em Fisiopatologia Experimental) - Faculdade de Medicina, Universidade de São Paulo, São Paulo, 2003. Acesso em: 2011-2018.

[2] SOARES DE OLIVEIRA, S et al. Experiência de Uso da Arthron na Transmissão de Cirurgias em Tempo-Real para Telessaúde, Programa de Pós-Graduação em Informática, Universidade Federal da Paraíba, João Pessoa, 2012

[3] P. PORTO. Neurocirurgia do HMASP é a primeira a utilizar Implante inédito no Brasil. Disponível em: <https://tinyurl.com/y5lr4ut5>. Acesso em: Mar 2019.

[4] BRAGA JUNIOR, W. Estratégia para armazenamento e recuperação de experiência multimídia em telessaúde: um estudo de caso no Projeto Ambiente de Vídeo Colaboração em Saúde (GTAVCS). 2013. 151 f. Tese (Doutorado em Informática) - Universidade Federal da Paraí-ba, João Pessoa, 2013.

[5] BRITO, T.D .Análise da colaboração nos Grupos de Interesse Especial (SIG) da Rede Universitária de Telessaúde (RUTE). 2016. 108f. Dissertação (Mestrado em Ciências) - Escola Paulista de Medicina, Universidade Federal de São Paulo. São Paulo, 2016.

[6] DA SILVA, C.I. et al. Análise dos processos videocolaborativos do Núcleo Telessaúde Brasil Redes Unifesp na Atenção Básica. In: ROESLER, V. \& CIUFFO, L. (Orgs.) O Futuro da Videocolaboração: Perspectivas. Porto Alegre: SBC, 2017. 